\title{
Employee performance in Jeddah national hospital in light of visual management
}

\begin{abstract}
Ali Dalain ${ }^{a^{*}}$
${ }^{a}$ College of Business, University of Jeddah, Saudi Arabia

CHRON I C L E A B S T RACT

Article history:

Received: December 22, 2019

Received in revised format:

January 302020

Accepted: February 15, 2020

Available online:

February 15, 2020

Keywords:

Visual management

Employees

Jeddah National Hospital

The aim of this study was to explore the degree of employee performance in light of visual management in Jeddah National Hospital and to identify if there were any statistical differences among respondents' estimations of their performance in terms of their work experience and training. The population of the study consisted of 820 employees, from which a sample, comprised 350 randomly chosen employees. Data were collected using a valid and reliable questionnaire and analyzed using IBM SPSS. The results underlined that the total degree of employee performance considering visual management was moderate. Particularly, employee performance on all dimensions; rules and regulations of visual management, as well as change, improvement and innovation, and work continuous follow-up, were moderate. Further, the results highlighted statistically significant differences between respondents due to work experience in favor of employees who have 15 years of experience or more and those who have 10 to less than 15 years of experience in favor of the former group. Additional differences were detected between employees with 10 to less than 15 years and those with less than 5 years of experience in favor of the group with 10 to less than 15 years. On the other hand, there were no statistically significant differences between respondents due to training courses.
\end{abstract}

\section{Introduction}

Organizations in general are required to respond quickly and consciously to instantaneous scientific and technological advancements as these organizations are open systems affect and affected by changes in their surrounding environment. Health service organizations are no exception. Expressly, a key aspect of service organizations' response, according to Akili (2015), is via reform and development of organizational tools and mechanisms in which organizations are trust to cope with new responsibilities imposed by state-of-the-art technologies in communications as well as knowledge-based evolutions. Healthcare services had been deemed as a life-and-death artery of the social service that countries keen to deliver and finance in order to preserve the ever-indispensable pillar of development, which is the human capital. Pointedly, medical professions have a high-priority role for the success of care processes in healthcare firms due to their significant effects on the provided healthcare services. These medical professions have been described as tremendously stressful compared to other professions (Shen et al., 2005), where workers gain experience in their daily practices on numerous cases of infected or injured people, workload, long working hours, evening shifts, competition with peers and doctors in light of low level of information sharing (Milutinovic et al., 2012; Steenkamp et al., 2017), in addition to emotional conflict with patients and their families, which increase stress (Tabak \& Korpak, 2007). On the basis of the developments in the psychological, social and administrative sciences during the last century, which had a significant effect on the administrative thought and the emergence of modern administrative schools aimed at improving the productivity of individuals to improve their performance, visual management has been introduced as a logical response to these developments (Barhamin, 2013). It is one of the most distinguished 
models of modern management practices produced by the enormous progressive movement in management in the world. This model is a result of the Japanese experience, which focuses on improving the organizational performance. The application of visual management in service organizations contributes to improving employee performance, meeting the need for a management style such as visual management and helps the organization survive and excel in terms of performance efficiently and effectively.

A general view of recent studies carried out on healthcare service organizations in the Kingdom of Saudi Arabia showed that researchers addressed concepts in these organizations such as lean methodology (Hassanain et al., 2017), self-management (Sabbah \& Al-Shehri, 2014), organizational change (Nafei, 2014), nurses' job satisfaction (Al-Ahmadi, 2002; Alshmemri et al., 2016), cultural intelligence (Nafei, 2013), total quality management (Alaraki, 2014), employee empowerment (Sweis et al., 2013), quality of healthcare services (Algahtani et al., 2017), hospitals performance (Ahmad et al., 2013), employees work-life balance (Azeem \& Altalhi, 2015), patient safety climate (Walston et al., 2010), sources of work stress among hospital staff (Al-Omar, 2003), burnout among healthcare providers (Bany-Hamdan et al., 2019), patient satisfaction (Ahmad et al., 2016), job design (Al-Maabadi et al., 2018), and employee motivation and job satisfaction in hospitals (Slimane, 2017). These are just examples of many works conducted on healthcare organizations in the Saudi Arabia. However, the researcher found no studies on employee performance considering visual management in healthcare service organization took place in this country. In order to explore the degree of employee performance in view of visual management in Jeddah National Hospital in terms of rules and regulations of visual management, as well as change, improvement and innovation along with work continuous follow-up, and to investigate differences in respondents' estimations of their performance keeping in mind visual management implementation that can be attributed to employees' work experience and number of training courses, the current study was designed to answer the following two questions:

(1) What is the degree of employee performance considering visual management in Jeddah National Hospital?

(2) Are there any statistical differences in respondents' estimations of their performance in view of visual management that can be attributed to their work experience and number of training courses?

\section{Literature review}

The literature on visual management in healthcare sector is still in its infancy. However, several studies were carried out in other sectors, from which a researcher can develop a clear understanding of this strategy based on its definitions, functions and significant, as can be seen in the following sections.

\subsection{Visual management definition}

Visual management has been defined as a management style used to manage problems as quickly as possible and to get rid of their root causes. It is also known as a vision-based management model that aims to improve the efficiency and effectiveness of management (Tezel, 2010). For Tezel et al. (2016) and Kurpjuweit et al. (2018), visual management is a strategy aimed at increasing information availability by providing individuals in the workplace with sensory aids to achieve flexibility in the flow of information and hence flow of work. Other definitions of visual management described it as a strategy of organizational control, measurement and improvement, which uses visual aids to make information more visible and to enhance communications in the workplace in order to support individuals' operations (Brady et al., 2018). For Parry and Turner (2006), visual management tools were developed in the context of lean thinking to guide processes in real time. Suski (2019) described visual management as a system used to increase organizational performance based on connecting organizational vision, values, objectives, and culture with management types like quality management, process management, etc., in which one or more of the human five senses are addressed.

\subsection{Visual management significance and functions}

Researchers highlighted several pros of visual management. Brady et al. (2018) described this strategy as an effective method used to enhance organizational performance by aligning organizational vision, core values, objectives as well as culture with work systems, operations, and elements depending on human sensory modalities. De Koning et al. (2006) regarded this strategy as an effective solution provided by lean thinking to solve organizational problems. A key benefit of visual benefit is that it supports the continuous flow of work by improving workers and managers' abilities to detect and correct organizational problems before they disrupt the entire system (Murata \& Katayama, 2010; Brady et al., 2018). In healthcare sector, visual management can be adopted to plan and control healthcare operations in hospitals and to achieve the process of continuous improvement (Verbano et al., 2017) and to eliminate processes duplication through consistent charge processes, recording patient details in fewer places, and non or less waiting of staff (Radnor et al., 2012). Regarding visual management functions, Tezel et al. (2009, 204) indicated that functions of visual management can be exemplified in terms of nine functions, including transparency of production process, following adequate procedures as a discipline, continuous improvement through innovation, job facilitation by visual means, on-the-job-training, creating shared ownership and a desired image, simplification based on constant control and information availability, management by facts using statistical data and unification through the elimination of horizontal, vertical, external and geographical barriers. Beynon-Davies and Lederman (2017) added that visual management is used extensively in the management of operations, especially in the improvement of operations in different sectors such as the manufacturing sector, and the health care sector. 


\subsection{Employee performance in light of visual management}

Employee performance, as a multidimensional variable, has been simply defined as individuals' contribution as measured in practical terms. This construct can be well understood considering abilities-motivation-opportunities (AMO), in which employee performance is operationalized in terms of three dimensions; individuals' abilities and skills, their motivation to utilize them in their job tasks, and opportunities available from them as represented by an adequate work environment (Pahos \& Galanaki, 2019). Employees have their own pivotal role in organizational performance, which can be measured by visual management, with an emphasis on human capital, by which several positive outcomes can be achieved such as increased employee productivity, enhanced quality, enriched motivations, advanced internal communications, improved information flow, and supported decision-making process (Suski, 2019). According to Kattman et al. (2012), there is a positive relationship between visual workplace and employee performance since the visual management plays a significant role in information sharing, employee self-direction and employee empowerment.

\section{Methodology}

\subsection{Study population and sample}

The population of this study consisted of 820 employees working at Jeddah National Hospital according to the hospital statistics in 2018/2019. A sample encompassed 370 employees were randomly selected from the hospital. A total of 370 questionnaires were distributed and 350 questionnaires were returned.

\subsection{Study instrument}

A questionnaire was developed referring to related works in order to gather the required data. It included three main sections: (1) employee personal data such as years of work experience and number of training courses. (2) work rules and regulations (items 1-12). (3) change, improvement and innovation (items 13-25), and (4) work continuous follow-up (items 26-35).

\subsection{Validity and reliability}

Validity was measured based on suggestions of an academic panel using a cut-off criterion of $80 \%$ agreement to include items. Three items were eliminated. The initial version was used to compute Cronbach's alpha. Table 1 shows the results of validity and reliability findings. It was found that the questionnaire that used in this study since Cronbach's alpha is greater than 0.7 (Bland \& Altman, 1997).

Table 1

Results of validity and reliability

\begin{tabular}{lccc}
\multicolumn{1}{c}{ Variables } & Items & Content validity & Cronbach's alpha \\
\hline Work rules and regulations & $1-12$ & $\checkmark$ & 0.87 \\
Change, improvement and innovation & $13-25$ & $\checkmark$ & 0.83 \\
Work continuous follow-up & $26-35$ & $\checkmark$ & 0.79 \\
\hline
\end{tabular}

\section{Results and discussion}

\subsection{Results of question 1}

Means (M) and standard deviations (SDs) were used to answer question 1 "what is the degree of employee performance in light of visual management in Jeddah National Hospital in terms of work rules and regulation, change, improvement and innovation, and work continuous follow-up?" The results are shown in Table 2.

Table 2

Means and standard deviations of employee performance degree in light of visual management

\begin{tabular}{clcccc}
\multicolumn{1}{c}{ Dimensions } & Means & SDs & Rank & Degree & Moderate \\
\hline No. & & 2.84 & 0.31 & \\
2 & Work rules and regulations & Change, improvement and innovation & 2.83 & 0.32 & 2 \\
3 & Work continuous follow-up & 2.80 & 0.38 & 3 \\
\hline- & Total & $\mathbf{2 . 8 2}$ & $\mathbf{0 . 3 9}$ & Moderate & Moderate \\
\hline
\end{tabular}

The results in Table 2 indicate that the total degree of employee's performance in light of visual management is moderate $(\mathrm{M}=2.82$, $\mathrm{SD}=0.39$ ). This result may be attributed to the modernity of visual management concept in service organizations in general and healthcare service organizations such as Jeddah National Hospital in particular, in addition to the lack of follow-up of the application of TQM standards in some sections of the hospital in terms of updating regulations and instructions that govern the work, and lack of new strategies that formulated to introduce change and continuous improvement. Specifically, the results illustrate that "work rules and regulations" ranked first $(\mathrm{M}=2.84, \mathrm{SD}=0.31)$, followed by "Change, improvement and innovation" in the second rank $(\mathrm{M}=2.38, \mathrm{SD}=0.32)$, then "Work continuous follow-up" in the third rank $(\mathrm{M}=2.80, \mathrm{SD}=0.38)$. The researcher attributed the reason behind the first rank of work rules and regulations to the concern of hospital staff to achieve visual management through 
strategic planning and to use an efficient and effective system to deliver patient reports to the concerned parties. On the other hand, the reason why works continuous follow-up ranked last is that the lack of some strategies and procedures for continuous improvement in the application of visual management through continuous follow-up mechanisms of work in some medical and administrative departments in the hospital. These results agree with Al-Hudhali (2015) who found a moderate correlational relationship between the implementation of visual management requirements and employee motivations, and with Ulhassan et al. (2014) who revealed that the implementation of lean methodology in hospitals had some influence on teamwork functioning. In contrast, the results were inconsistent with Hammam (2012) who revealed a high degree of employee awareness in healthcare organizations in the concept of healthcare service quality, requirements of continuous improvement and six-sigma methodology, and with Brahamin's (2012) results that showed an excellent level of performance considering visual management.

\section{Work rules and regulations}

Table 3 displays the total degree of employees' estimations of work and regulations as well as the degrees of items as assessed by means and standard deviations.

Table 3

Means and standard deviations of work rules and regulations

\begin{tabular}{|c|c|c|c|c|c|}
\hline No. & Dimensions & Means & SDs & Rank & Degree \\
\hline 12 & Integrity and transparency within business rules & 2.93 & 0.32 & 1 & Moderate \\
\hline 1 & $\begin{array}{l}\text { A comprehensive strategic plan in line with the mission, goals and values of the hospital } \\
\text { and the requirements of the Ministry of Health }\end{array}$ & 2.92 & 0.27 & 2 & Moderate \\
\hline 5 & An efficient and effective system for communicating patient reports to concerned parties & 2.87 & 0.41 & 3 & Moderate \\
\hline 11 & the delegation of authority to enable staff in work established rules & 2.84 & 0.42 & 4 & Moderate \\
\hline 10 & Effective and objective methods in evaluating business rules & 2.80 & 0.45 & 5 & Moderate \\
\hline 3 & Realistic goals that can be measured & 2.78 & 0.51 & 6 & Moderate \\
\hline 7 & Concerned party's involvement in the development of rules and work plan & 2.73 & 0.55 & 7 & Moderate \\
\hline 6 & The development of programs of administrative work that contain multiple activities & 2.70 & 0.58 & 8 & Moderate \\
\hline 9 & Business rules and regulations follow its requirements & 2.65 & 0.95 & 9 & Moderate \\
\hline 8 & $\begin{array}{l}\text { The rules of work are comprehensive to define tasks and performance measurement } \\
\text { standards }\end{array}$ & 2.63 & 0.77 & 10 & Moderate \\
\hline 4 & $\begin{array}{l}\text { decision-making based on assessment of results to develop business improvement strat- } \\
\text { egies }\end{array}$ & 2.62 & 0.85 & 11 & Moderate \\
\hline 2 & Organization of the work plan with emphasis on administrative and technical aspects & 2.61 & 0.92 & 12 & Moderate \\
\hline- & Total & 2.76 & 0.41 & - & Moderate \\
\hline
\end{tabular}

The results in Table 3 clarify that the total degree of employee performance considering visual management in terms of work rules and regulations is moderate $(\mathrm{M}=2.76, \mathrm{SD}=0.41)$. The degrees of all items were moderate. Item no. 12 "integrity and transparency within business rules" ranked first with a moderate degree $(\mathrm{M}=2.93, \mathrm{SD}=0.32)$ and this may be due to the interest of the managers of the hospital in in establishing the values of transparency and discipline in work and striving towards applying regulations and instructions to everyone. Item no. 2 "organization of the work plan with emphasis on administrative and technical aspects" ranked last $(\mathrm{M}=2.61, \mathrm{SD}=0.92)$ and this may be due to the lack of written plans in which administrative and technical management requirements are combined with regard to medical work and due to the lack of coordination between the medical team and the administrative team may lead to the absence of action plans. Based on these results, it was concluded that there is a need for building a strategy to develop the rules of work so as to regulate relationships between the director of the hospital and his subordinates.

\section{Chang, improvement and innovation}

Table 4 demonstrates the total degree of employees' estimations of change, improvement and innovation dimension as well as the degrees of items as evaluated by means and standard deviations.

Table 4

Means and standard deviations of change, improvement and innovation

\begin{tabular}{|c|c|c|c|c|c|}
\hline No. & Dimensions & Means & SDs & Rank & Degree \\
\hline 26 & A culture of change among employees & 2.91 & 0.37 & 1 & Moderate \\
\hline 18 & An adequate work environment for innovation and creativity & 2.86 & 0.43 & 2 & Moderate \\
\hline 13 & Simple and effective business rules for change requirements & 2.84 & 0.44 & 3 & Moderate \\
\hline 21 & Training opportunities to improve employee performance & 2.82 & 0.52 & 4 & Moderate \\
\hline 22 & A plan to improve the level of employee performance & 2.81 & 0.46 & 5 & Moderate \\
\hline 20 & Stimulating employees to conduct scientific research & 2.76 & 0.54 & 6 & Moderate \\
\hline 16 & Financial and non-financial incentives to improve performance & 2.75 & 0.55 & 7 & Moderate \\
\hline 17 & Data availability to enhance work & 2.74 & 0.58 & 8 & Moderate \\
\hline 15 & Changes in current policies & 2.60 & 0.65 & 9 & Moderate \\
\hline 19 & Employee participation in work-related decisions & 2.55 & 0.80 & 10 & Low \\
\hline 23 & Objective systems to evaluate performance & 2.45 & 0.95 & 11 & Low \\
\hline 24 & Adequate utilization of available resources & 2.43 & 1.08 & 12 & Low \\
\hline 25 & Employee participation in problem-solving & 2.40 & 1.09 & 13 & Low \\
\hline- & Total & 2.69 & 0.89 & - & Moderate \\
\hline
\end{tabular}


The results in Table 4 point out that the total degree of employee performance in view of visual management in terms of change, improvement and innovation is moderate $(\mathrm{M}=2.69, \mathrm{SD}=0.89)$. Item no. 26 "a culture of change among employees" ranked first $(\mathrm{M}=2.91, \mathrm{SD}=0.37)$ and this may be due to keenness of the managers to implement change management in the hospital's working environment. However, the culture of change among some of the employees is still rejected, as some of them have long experience or may be because of lack of training. The degrees of all items were moderate except four items with low degrees including employee participation in work-related decisions, availability of objective systems to evaluate performance, adequate utilization of available resources and employee participation in problem-solving.

\section{Work continuous follow-up}

Table 5 clarifies the total degree employees' estimations of work continuous follow-up dimension as well as the degrees of items as evaluated by means and standard deviations.

Table 5

Means and standard deviations of work continuous follow-up

\begin{tabular}{|c|c|c|c|c|c|}
\hline No. & $\begin{array}{c}\text { Dimensions } \\
\end{array}$ & Means & SDs & Rank & Degree \\
\hline 6 & Recording urgent needs and following up implementation & 2.87 & 0.63 & 1 & Moderate \\
\hline 2 & Follow-up mechanisms to spread the culture of excellence & 2.86 & 0.58 & 2 & Moderate \\
\hline 3 & Continuous assessment of employee's performance & 2.83 & 0.54 & 3 & Moderate \\
\hline 7 & Follow-up of the preparation of emergency plans & 2.82 & 0.67 & 4 & Moderate \\
\hline 5 & Follow-up procedures to achieve quality of service & 2.78 & 0.49 & 5 & Moderate \\
\hline 1 & Procedural guides to follow up the implementation of & 2.74 & 0.66 & 6 & Moderate \\
\hline 4 & Field follow-up of departments achievements & 2.69 & 0.61 & 7 & Moderate \\
\hline 10 & Daily Follow up of complaints of citizens in various media & 2.58 & 0.74 & 8 & Low \\
\hline 9 & always Follow up of sudden accidents & 2.50 & 0.73 & 9 & Low \\
\hline 8 & Follow up of instructions implementation & 2.44 & 0.89 & 10 & Low \\
\hline- & Total & 2.71 & 0.88 & - & Moderate \\
\hline
\end{tabular}

The results in Table 5 indicate that the total degree of employee performance in light of visual management in terms of work continuous follow-up is moderate $(\mathrm{M}=2.71, \mathrm{SD}=0.88)$. Item no. 6 "recording urgent needs and following up implementation" in the first rank $(\mathrm{M}=2.87, \mathrm{SD}=0.63)$ and this may be due to the lack of a system to follow the administrative and technical needs of the hospital and to follow up spreading the culture of excellence in the working environment of the hospital. Most of the items were moderate except three items related to daily follow up of complaints of citizens in various media, always follow up of sudden accidents and follow up of instructions implementation. Consequently, there is a need to implement visual management to improve performance via continuous follow-up, learn from errors and correct work conditions.

\subsection{Results and discussion of question 2}

One-way ANOVA was used to answer question 2 "are there any statistical differences in respondents' estimations of their performance in view of visual management that can be attributed to their work experience and number of training courses?"

\section{Work experience}

Table 6 shows the results of ANOVA test that used to identify if there are any differences between respondents' estimations of their performance level due to work experience.

Table 6

Results of ANOVA for difference in employee responses due to work experience

\begin{tabular}{|c|c|c|c|c|c|c|}
\hline Dimension & Source & Sum of squares & df & Mean square & $\mathbf{F}$ & Sig.* \\
\hline \multirow{3}{*}{$\begin{array}{l}\text { Work rules and } \\
\text { regulations }\end{array}$} & between groups & 18.516 & 3 & 6.172 & \multirow{3}{*}{120.07} & \multirow{3}{*}{0.000} \\
\hline & within groups & 25.598 & 498 & 0.051 & & \\
\hline & Total & 44.114 & 501 & & & \\
\hline \multirow{3}{*}{$\begin{array}{l}\text { Chang, improvement } \\
\text { and innovation }\end{array}$} & between groups & 44.037 & 3 & 14.679 & \multirow{3}{*}{251.95} & \multirow{3}{*}{0.000} \\
\hline & within groups & 29.014 & 498 & 0.058 & & \\
\hline & Total & 73.051 & 501 & & & \\
\hline \multirow{3}{*}{$\begin{array}{l}\text { Work continuous } \\
\text { follow-up }\end{array}$} & between groups & 43.709 & 3 & 14.570 & \multirow{3}{*}{304.01} & \multirow{3}{*}{0.000} \\
\hline & within groups & 23.867 & 498 & 0.048 & & \\
\hline & Total & 67.576 & 501 & & & \\
\hline \multirow{3}{*}{ Total } & between groups & 40.868 & 3 & 13.623 & \multirow{3}{*}{644.24} & \multirow{3}{*}{0.000} \\
\hline & within groups & 10.530 & 498 & 0.021 & & \\
\hline & Total & 51.398 & 501 & & & \\
\hline
\end{tabular}

* significant at $\alpha \leq 0.05$

The results in Table 6 indicate that there are statistically significant differences between the means of employees' responses on their performance considering visual management $(F=644.24, \mathrm{P}$-value $=0.000)$. Particularly, there are statistically significant differences 
between the means of employees' responses in terms of work rules and regulations ( $\mathrm{F}=120.07$, $\mathrm{P}$-value $=0.000)$, change, improvement and innovation $(\mathrm{F}=251.95$, $\mathrm{P}$-value $=0.000)$, and work continuous follow-up $(\mathrm{F}=304.01, \mathrm{P}$-value $=0.000)$.

The Scheffe test was used to conduct post-hoc comparisons to identify which pairs of means are significant. The results in Table 6 indicate that there are statistically significant differences between employees' estimations of their performance due to work experience in favor of employee with long experiences, 15 - more than 15 years and 10 - less than 15 years in comparison with employees who have less than 5 years of experience and 5 - less than 10 years. Further, there are statistically significant differences between employees with less than 5 years and employees with 5 - less than 10 years of experience in favor of those with 5 - less than 10 years. This result may be explained by the fact that the employees who have higher experience acquired more knowledge on the methods, techniques and strategies of continuous improvement and application of visual management approach, unlike employees who have less experience on this side. This result is inconsistent with the results of the Ibrahim (2014) who found no differences due to years of experience.

Table 7

Results of Scheffe test

\begin{tabular}{|c|c|c|c|c|}
\hline Dimension & Experience & Mean & Less than 5 years & 5 -less than 10 years \\
\hline \multirow{4}{*}{$\begin{array}{l}\text { Work rules and } \\
\text { regulations }\end{array}$} & Less than 5 years & 2.449 & - & - \\
\hline & $5-10$ years & 2.284 & $0.37 *$ & - \\
\hline & 10 - less than 15 years & 2.918 & $0.047^{*}$ & $0.09 *$ \\
\hline & 15 - more than 15 years & 2.979 & $0.53 *$ & $0.15^{*}$ \\
\hline \multirow{4}{*}{$\begin{array}{l}\text { Chang, improvement and } \\
\text { innovation }\end{array}$} & Less than 5 years & 2.144 & - & - \\
\hline & $5-10$ years & 2.701 & $0.55^{*}$ & - \\
\hline & 10 - less than 15 years & 2.856 & $0.71 *$ & $0.16^{*}$ \\
\hline & 15 - more than 15 years & 2.962 & $0.82 *$ & $0.26^{*}$ \\
\hline \multirow{4}{*}{$\begin{array}{l}\text { Work continuous } \\
\text { follow-up }\end{array}$} & Less than 5 years & 2.187 & - & - \\
\hline & $5-10$ years & 2.803 & $0.62 *$ & - \\
\hline & 10 - less than 15 years & 2.950 & $0.76^{*}$ & $0.015^{*}$ \\
\hline & 15 - more than 15 years & 2.992 & $0.80 *$ & $0.19 *$ \\
\hline \multirow{4}{*}{ Total } & Less than 5 years & 2.200 & - & - \\
\hline & $5-10$ years & 2.735 & $0.53 *$ & - \\
\hline & 10 - less than 15 years & 2.908 & $0.71 *$ & $0.17^{*}$ \\
\hline & 15 - more than 15 years & 2.984 & $0.78 *$ & $0.25 *$ \\
\hline
\end{tabular}

* significant at $\alpha \leq 0.05$

Training courses

Table 8 shows the results of ANOVA test that is used to identify if there are any differences between respondents' estimations of their performance level due to training courses. It was noted that there are no significant differences between employees' responses on their performance considering visual management $(\mathrm{F}=1.144$, $\mathrm{P}$-value $=0.320)$, which is greater than the significance level 0.05 . As well, the results show that there are no significant differences due to training courses in terms of work rules and regulations, change, improvement and innovation, in addition to work continuous follow-up. The reason for this can be explained by the similarity of circumstances among respondents regardless of the training courses they attend, and some of them are participants and have training courses in quality, and therefore their performance according to visual management is similar because they are influenced by the same factors that regulate the work. This result agrees with Ibrahim (2014) who found no significant results due to training courses.

Table 8

Results of ANOVA for difference in employee responses due to training courses

\begin{tabular}{|c|c|c|c|c|c|c|}
\hline Dimension & Source & Sum of squares & df & Mean square & $\mathbf{F}$ & Sig.* \\
\hline \multirow{3}{*}{$\begin{array}{l}\text { Work rules and } \\
\text { regulations }\end{array}$} & between groups & 0.107 & 2 & 0.054 & \multirow{3}{*}{2.979} & \multirow{3}{*}{0.053} \\
\hline & within groups & 6.238 & 347 & 0.018 & & \\
\hline & Total & 6.345 & 349 & & & \\
\hline \multirow{3}{*}{$\begin{array}{l}\text { Chang, improvement } \\
\text { and innovation }\end{array}$} & between groups & 0.024 & 2 & 0.012 & \multirow{3}{*}{0.454} & \multirow{3}{*}{0.635} \\
\hline & within groups & 9.111 & 347 & 0.026 & & \\
\hline & Total & 9.135 & 349 & & & \\
\hline \multirow{3}{*}{$\begin{array}{l}\text { Work continuous } \\
\text { follow-up }\end{array}$} & between groups & 0.105 & 2 & 0.053 & \multirow{3}{*}{2.156} & \multirow{3}{*}{0.117} \\
\hline & within groups & 8.472 & 347 & 0.024 & & \\
\hline & Total & 8.577 & 349 & & & \\
\hline \multirow{3}{*}{ Total } & between groups & 0.040 & 2 & 0.020 & \multirow{3}{*}{1.144} & \multirow{3}{*}{0.320} \\
\hline & within groups & 6.034 & 347 & 0.017 & & \\
\hline & Total & 0.074 & 349 & & & \\
\hline
\end{tabular}

* significant at $\alpha \leq 0.05$

\section{Policy implications and imitation}

The aim of this study was to explore the degree of employees' performance in light of visual management and to identify difference between employees' estimations on their performance due to work experience and training. The results have shown that the total degree of employee performance was moderate. Particularly, the results indicated that employee performance was moderate on the three dimensions under study; work rules and regulations, change, improvement and innovation, and work continuous follow-up. 
On the other hand, the result revealed significant differences between respondents' in terms of their work experience but not in their training courses. Based on these results, managers of the hospital are required to adopt new strategies like visual management to improve employees' performance. They are also requested to train their employees on preparing preventive and alternative plans to face problems and to be able apply these plans from the site of the event. Additionally, managers of the hospital should develop continuous follow-up methods among the leaders in the hospitals through activating the technology in follow-up and implementation of the actual situations that occur in the hospital. This study is limited by its cross-sectional design and by its sample that selected from Jeddah National Hospital. Therefore, future studies are required to conduct an analysis of the performance of employees at the Jeddah National Hospital and other hospitals according to the latest administrative trends such as visual management.

\section{References}

Ahmad, A. E., Al-Qarni, A. A., Alsharqi, O. Z., Qalai, D. A., \& Kadi, N. (2013). The impact of marketing mix strategy on hospitals performance measured by patient satisfaction: an empirical investigation on Jeddah private sector hospital senior managers' perspective. International Journal of Marketing Studies, 5(6), 210-227.

Ahmad, A. M., Alghamdi, M. A., Alghamdi, S. A., Alsharqi, A. Z., \& Al-Borie, H. M. (2016). Factors influencing patient satisfaction with pharmacy services: An empirical investigation at King Fahd Armed Forces Hospital, Saudi Arabia. International Journal of Business Management, 11, 272-280.

Akili, O. (2015). Contemporary human resource management - Strategic dimension. Amman: Dar Wael for publishing, Printing and Distribution.

Al-Ahmadi, H. A. (2002). Job satisfaction of nurses in Ministry of Health Hospitals in Riyadh, Saudi Arabia. Saudi Medical Journal, 23(6), 645-650.

Alaraki, M. S. (2014). The impact of critical total quality management practices on hospital performance in the Ministry of Health Hospitals in Saudi Arabia. Quality Management in Healthcare, 23(1), 59-63.

Algahtani, H., Aldarmahi, A., Manlangit Jr, J., \& Shirah, B. (2017). Perception of hospital accreditation among health professionals in Saudi Arabia. Annals of Saudi medicine, 37(4), 326.

Al-Hudhali, W. (2015). The possibility of applying the (VM) in the educational offices in Makkah's region and its relationship with motivation of workers. A Master thesis, Umm Al-Qura University, The Kingdom of Saudi Arabia.

Al-Maabadi, A., Salem, O., \& Baddar, F. (2018). The relationship between job design and nurses' satisfaction. SOJ Nur Health, Care 4(2), 1-9.

Al-Omar, B. A. (2003). Sources of work-stress among hospital-staff at the Saudi MOH. Economics and Administration, 17(1), 316.

Alshmemri, M., Shahwan-Akl, L., \& Maude, P. (2016). Job satisfaction of Saudi nurses working in Makkah region public hospitals, Saudi Arabia. Life Science Journal, 13(12), 22-33.

Azeem, S. M., \& Altalhi, H. (2015). Role of perceived work-life balance and job satisfaction in developing organizational commitment among hospital employees in Saudi Arabia. International Journal of Academic Research in Business and Social Sciences, 5(12), 185-197.

Bany Hamdan, A., Alshammary, S., \& Javison, S. (2019). Burnout among healthcare providers in a comprehensive cancer center in Saudi Arabia. Cureus 11(1), 1-14

Barhamin, A. (2013). The performance level of the Saudi universities under visual management and Kaizen concepts as perceived by their directors and deputy directors. A doctorate dissertation, Umm Al-Qura University, The Kingdom of Saudi Arabia.

Beynon-Davies, P., \& Lederman, R. (2017). Making sense of visual management through affordance theory. Production Planning \& Control, 28(2), 142-157.

Bland, J. M., \& Altman, D. G. (1997). Statistics notes: Cronbach's alpha. BMJ, 314(7080), 572.

Brady, D., Tzortzopoulos, P., Rooke, J., Formoso, C., \& Tezel, A. (2018). Improving transparency in construction management: A visual planning and control model. Engineering, Construction and Architectural Management, 25(10), $1277-1297$.

De Koning, H., Verver, J. P., van den Heuvel, J., Bisgaard, S., \& Does, R. J. (2006). Lean six sigma in healthcare. Journal for Healthcare Quality, 28(2), 4-11.

Hammam, A. (2012). Using Six-Sigma to improve service quality: A field study on healthcare sector in Al-Taif City. Commerce and Finance Journal, 4, 191-232.

Hassanain, M., Zamakhshary, M., Farhat, G., \& Al-Badr, A. (2017). Use of lean methodology to improve operating room efficiency in hospitals across the Kingdom of Saudi Arabia. The International Journal of Health Planning and Management, 32(2), 133146.

Ibrahim, Y. (2014). Impact of open management systems in capacity support competitiveness of Egyptian University hospitals, Cairo University Hospitals Model. Journal of Arab Research and Studies - Egypt, 61, 275-328.

Kattman, B., Corbin, T. P., Moore, L. E., \& Walsh, L. (2012). Visual workplace practices positively impact business processes. Benchmarking: An International Journal, 19(3), 412-430.

Kurpjuweit, S., Reinerth, D., Schmidt, C., \& Wagner, S. (2018). Implementing visual management for continuous improvement: Barriers, success factors and best practices. International Journal of Production Research, 1-15.

Milutinovic, D., Golubovic, B., Brkic, N., \& Prokes, B. (2012). Professional Stress and Health among Critical Care Nurses in Serbia, Arh Hig Rada Toksikol, 63, 171-180.

Murata, K., \& Katayama, H. (2010). Development of Kaizen case-base for effective technology transfer: A case of visual management technology. International Journal of Production Research, 48(16), 4901-4917. 
Nafei, W. A. (2013). The impact of cultural intelligence on employee job performance: an empirical study on King Abdel-Aziz Hospital in Al-Taif Governorate, Kingdom of Saudi Arabia. International Journal of Business and Management, 8(1), 26.

Nafei, W. A. (2014). Assessing employee attitudes towards organizational commitment and change: The case of King Faisal Hospital in Al-Taif Governorate, Kingdom of Saudi Arabia. Journal of Management and Sustainability, 4(1), 204-219.

Pahos, N., \& Galanaki, E. (2019). Staffing practices and employee performance: the role of age. In Evidence-based HRM: a Global Forum for Empirical Scholarship (Vol. 7, No. 1, pp. 93-112). Emerald Publishing Limited.

Parry, G. C., \& Turner, C. E. (2006). Application of lean visual process management tools. Production Planning \& Control, 17(1), 77-86.

Radnor, Z. J., Holweg, M., \& Waring, J. (2012). Lean in healthcare: the unfilled promise. Social Science \& Medicine, 74(3), 364371.

Sabbah, K. O. A., \& Al-Shehri, A. A. (2014). Practice and perception of self-management among diabetics in Taif, KSA: impact of demographic factors. International Journal of Medical Science and Public Health, 3(3), 277-285.

Shen, H.-C., Cheng, Y., Tsai, P.-J., Lee, S.S., \& Guo, Y.L. (2005). Occupational stress in nurses in psychiatric institutions in Taiwan. Journal of Occupational Health, 47, 218-225

Slimane, N. S. (2017). Motivation and job satisfaction of pharmacists in four hospitals in Saudi Arabia. Journal of Health Management, 19(1), 39-72.

Steenkamp, L. P., Hagedorn-Hansen, D., \& Oosthuizen, G. (2017). Visual management system to manage manufacturing resources. Procedia Manufacturing, 8, 455-462.

Suski, C. A. (2019). The importance of visual management as a motivator of human capital and optimization of the results of the productive system. Asian Basic and Applied Research Journal, 1(1), 1-8.

Sweis, R. J., Al-Mansour, A., Tarawneh, M., \& Al-Dweik, G. (2013). The impact of total quality management practices on employee empowerment in the healthcare sector in Saudi Arabia: A study of King Khalid Hospital. International Journal of Productivity and Quality Management, 12(3), 271-286.

Tabak, N., \& Koprak, O. (2007) Relationship between how nurses resolve their conflicts with doctors, their stress and job satisfaction. Journal of Nursing Management, 11, 321-331

Tezel, A., Koskela, L., \& Tzortzopoulos, P. (2016). Visual management in production management: A literature synthesis. Journal of Manufacturing Technology Management, 27(6), 766-799.

Tezel, B., Koskela, L., \& Tzortzopoulos, P. (2009). The functions of visual management. Paper presented at the 6th International Research Symposium, Salford, UK, January 27-28.

Tezel, B., Koskela, L., \& Tzortzopoulos, P. (2010). Visual management in construction: Study report on Brazilian cases. Salford, UK: University of Salford.

Ulhassan, W., Westerlund, H., Thor, J. Sandahl, C., \& Schwarz, U. (2014). Does Lean implementation interact with group functioning? Journal of Health Organization and Management, 28(2), 196-213.

Verbano, C., Crema, M., \& Nicosia, F. (2017). Visual management system to improve care planning and controlling: the case of intensive care unit. Production Planning \& Control, 28(15), 1212-1222.

Walston, S. L., Al-Omar, B. A., \& Al-Mutari, F. A. (2010). Factors affecting the climate of hospital patient safety: A study of hospitals in Saudi Arabia. International Journal of Health Care Quality Assurance, 23(1), 35-50.

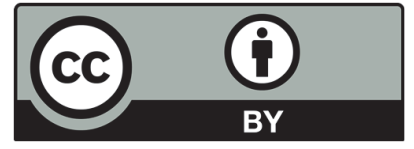

(C) 2020 by the authors; licensee Growing Science, Canada. This is an open access article distributed under the terms and conditions of the Creative Commons Attribution (CC-BY) license (http://creativecommons.org/licenses/by/4.0/). 